\title{
Combining Taguchi method and DEAR method for multi- objective optimization of grinding process
} \author{
Nguyen Anh Tuan ${ }^{2, *}$ \\ ${ }^{1} \mathrm{Ha}$ Noi University of Industry, Vietnam \\ ${ }^{2}$ University of Economics - Technology for Industries, Vietnam \\ ${ }^{3}$ Nguyen Tat Thanh University, Ho Chi Minh City, Vietnam \\ ${ }^{4}$ Electric Power University, Vietnam \\ ${ }^{5}$ Thai Nguyen University of Technology, Thai Nguyen, Vietnam
}

Do Duc Trung ${ }^{1}$, Nguyen Huu Quang ${ }^{2}$, Dang Quoc Cuong ${ }^{3}$, Nguyen Hong Linh ${ }^{4}$, Nguyen Van Tuan ${ }^{1}$, Le Xuan Hung ${ }^{5}$, and

\begin{abstract}
In this paper, a study on multi-objective optimization of the cylindrical grinding process is presented. The experimental material used in this study is X12M steel. The two output parameters of the grinding process considered in this study are surface roughness and material removal rate (MRR). The cutting mode parameters including cutting speed, feed rate, and cutting depth have been selected as input parameters of the experimental process. Experimental matrix by Taguchi method has been used to design a matrix with 27 experiments. Analysis of experimental results by Pareto chart has determined the effect of input parameters on output parameters. The Data Envelopment Analysis-based Ranking (DEAR) method has been applied to determine the values of input parameters to simultaneously ensure the two criteria of minimum surface roughness and maximum MRR. Finally, the development direction for further studies has also been recommended in this study.
\end{abstract}

Keywords: cylindrical grinding, X12M steel, surface roughness, MRR, multi-objective optimization, Taguchi, DEAR

\section{Introduction}

Grinding is a method known for a long time because of its machining ability to ensure high accuracy and surface gloss. It is the most commonly used method for the final machining of critical surfaces $[1,2]$. Surface roughness directly effects on the workability and durability of the product, so it is considered one of the most important and popular parameters to evaluate the grinding process. Besides, MRR is a direct parameter to evaluate the productivity of the machining process, so this parameter is also often chosen as one of the criteria to evaluate the grinding process [1-4]. The studies on the grinding process in general and the external cylindrical grinding process, in particular, to ensure the workpiece surface of the machine with slight surface roughness and large MRR have been performed by many authors. In those studies, the authors have often determined the optimal value of parameters of the machining process to ensure the minimum surface roughness or the maximum MRR. This problem is known as the optimization of the grinding process.

When studying the optimization of the grinding process, many authors have used the Taguchi method to design the experimental matrix. The reason why the Taguchi method is used a lot in designing experimental matrices is that it will be found that the Taguchi method has a much smaller number of experiments when compared with some other matrix design methods. An advantage that only Taguchi method has is that it is capable of designing a matrix with the first parameter being a qualitative parameter (not a quantitative parameter) $[5,6]$.

For studying the optimization of the external cylindrical grinding process, to ensure the minimum surface roughness, the Taguchi method has been applied to design the experimental matrix, followed by the Signal-to-Noise ratio $(\mathrm{S} / \mathrm{N})$ to determine the optimal 
value of cutting speed, feed rate, and cutting depth when grinding EN-19 steel [7], when grinding 304 stainless steel [8], when grinding EN-31 steel and mild steel [9], when grinding EN-19 [10]; to determine the optimal value of cutting speed, feed rate, cutting depth and billet hardness when grinding EN-19 steel [11]; to determine the optimal value of cutting speed, workpiece speed, grain size, cutting depth, coolant flow, and grinding stroke number when grinding EN-47 steel [12]; to determine grain size, cutting depth and type of coolant when grinding Inconel 718 alloy [13]; to determine the value of cutting speed, workpiece speed, cutting depth, feed rate and grinding wheel material when grinding EN8 steel [14].

To ensure the minimum value of MRR, the Taguchi method and $\mathrm{S} / \mathrm{N}$ ratio analysis method have also been applied to determine the optimal value of cutting speed and feed rate when grinding EN-31 steel and mild steel [9]; when grinding EN-19 steel [10], when grinding IS319 Brass [15], when grinding AISI 316 steel [16]; to determine the optimal value of cutting speed, workpiece speed, grain size, cutting depth, coolant flow, and grinding stroke number when grinding EN-47 steel [12]; when grinding EN21AM steel [17,18].

A number of above studies show that there are many parameters affecting surface roughness and MRR, in which the parameters of cutting parameters often selected as the input parameters of the experimental process when grinding. The machine operator can easily adjust these parameters. However, only conducting the experimental process by Taguchi matrix and $\mathrm{S} / \mathrm{N}$ ratio analysis can only guarantee a certain goal in each study, either the minimum roughness or the maximum MRR. In order to be able to simultaneously ensure the two criteria of the grinding process, inclusive of the minimum surface roughness and the maximum MRR, it is necessary to study the multi-objective optimization of the grinding process.

$\mathrm{X} 12 \mathrm{M}$ steel is representative of high alloy steel. This type of steel has the characteristics of high hardness after high treatment and high wear resistance. This type of steel is often used to manufacture parts and/or components such as transmission shafts, gears, extrusion dies, and cutters in the logging and woodworking industry. However, studies on the determination of the optimal value of cutting parameters for simultaneous assurance of the two criteria inclusive of the minimum surface roughness and the maximum MRR have not been published by any works.

DEAR is a method used to generate multiobjective optimization that was first introduced in 2002 [19]. This method has been used in several studies such as multi-objective optimization of AISI 1055 steel turning process [20]; multi-objective optimization of Ti-6Al-4V alloy turning process [21]; multi-objective optimization of SAE420 steel grinding with segmented grinding wheel process [22]; multiobjective optimization of electrical discharge machining (EDM) for AA 6082 material [23], etc. However, there have been no published studies on the application of this method in multi-objective optimization of the cylindrical grinding process in general and $\mathrm{X} 12 \mathrm{M}$ steel cylindrical grinding process in particular.

Based on the above analysis, in this study, an experiment of X12M steel cylindrical grinding process was conducted. The experimental matrix was designed by the Taguchi method, with the input parameters being the cutting parameters. Also, analyzing experimental results to determine the effect of input parameters on surface roughness and MRR was carried out. The determination of the optimal value of input parameters to simultaneously ensure the minimum surface roughness and the maximum MRR was conducted by DEAR method.

\section{DEAR method}

The purpose of the experimental process of this study is to ensure the minimum value of surface roughness (Ra) and the maximum value of MRR. Thus, it is necessary to determine the value of input parameters to ensure the objectives as set out. The DEAR method will be applied in this study to carry out the above-stated work. Summary of steps when applying the DEAR method is as follows [19]:

- Determine the weight of each response for all experiments. This value is calculated as the ratio of the value of each response to the sum of all responses.

- Transfer the response data to the weight data by multiplying the observed data by its own weight.

- Divide the data as small as possible by the one as small as possible.

- Consider this value as the multi response performance index (MRPI)

The method to determine MRPI in this study is carried out in accordance with the following formula:

$$
M R P I=W_{R_{a}} * R_{a}+W_{M R R} * M R R
$$


In formula (1), the weight of the responses is calculated as follows:

$$
\begin{gathered}
W_{R_{a}}=\frac{R_{a}}{\sum R_{a}} \\
W_{M R R}=\frac{\frac{1}{M R R}}{\sum \frac{1}{M R R}}
\end{gathered}
$$

\section{$3 \quad$ Grinding process experiment}

\subsection{Experimental system}

Experiments have been conducted on an external cylindrical grinder with the serial number $3 E 153$ (Russia). The adjustment of cutting depth when grinding is carried out by means of verner. Each mark on the verner corresponds to the value of $0.005 \mathrm{~mm}$. The longitudinal feed rate can be steplessly adjusted as this mechanism is operated by a hydraulic system. The machine has also been fitted with a frequency converter to be able to adjust the rotational speed of the grinding wheel in stepless mode.

In this work, the workpiece material was X12M steel. The experimental sample has a diameter of $30 \mathrm{~mm}$, a length of $340 \mathrm{~mm}$, of which the grinding length is 300 $\mathrm{mm}$, the remaining length is $40 \mathrm{~mm}$, which is the position for placing a pair of rests. Before the experiment, the steel sample has been turned and treated by heat to reach a hardness of 56-58 HRC.

The grinding wheel used in the experiment is an aluminum oxide grinding wheel manufactured by Hai Duong Grinding Wheel Factory (Vietnam). The grinding wheel has a grain size of 80 , medium hardness, ceramic binder, cylindrical grinding wheel type, its outer diameter is $320 \mathrm{~mm}$, its thickness is 28 $\mathrm{mm}$, the hole diameter is $160 \mathrm{~mm}$, and the speed limit, as recommended by the manufacturer, is $35 \mathrm{~m} / \mathrm{s}$. All these parameters have been included in the serial number of the grinding wheel as Cn80.TB1.G.V1.320x28x160x35m/s.

To measure the surface roughness, a roughness meter SJ201 has been used. The machine is set to the standard length of $0.8 \mathrm{~mm}$ and the measuring head diameter of $0.005 \mathrm{~mm}$. During the measurement, the measuring head moves parallel to the centerline of the workpiece, i. e. perpendicular to the vector of cutting velocity. Each experimental sample is measured at least three times at three different locations. The roughness value at each experiment is the average value of consecutive measurements.

MRR is reckoned as the amount of material removed in one minute. This parameter is calculated by taking the difference of sample volume before grinding minus sample volume after grinding and then divided by the grinding time, of which the grinding time is calculated as the grinding length divided by the movement speed of the grinding wheel (feed rate).

In the grinding process, other parameters have constant values, including the workpiece speed of 318 $\mathrm{rev} / \mathrm{min}$ (corresponding to $30 \mathrm{~m} / \mathrm{s}$ ), using a 1 -grain diamond dresser, the dressing depth is $0.02 \mathrm{~mm}$, the dressing feed rate is $150 \mathrm{~mm} / \mathrm{min}$. A $10 \%$ emulsion solution has been used to irrigate the cutting area with a flow rate of 16 liters $/ \mathrm{min}$.

\subsection{Experiment design}

The selected three parameters of cutting parameters, including cutting speed, feed rate, and cutting depth, are the input parameters of the experimental process. For each of the input parameters, three levels of value were selected as shown in Table 1, which were selected within their range when grinding this steel [24]. The experimental matrix was designed in accordance with Taguchi method with a total of 27 experiments, as shown in Table 2 .

Table 1. Values at the levels of input parameters

\begin{tabular}{|l|c|c|c|c|c|}
\hline Parameters & \multirow{2}{*}{ Symbol } & \multirow{2}{*}{ Unit } & \multicolumn{3}{|c|}{ Value at levels } \\
\cline { 4 - 6 } & & 1 & 2 & 3 \\
\hline $\begin{array}{l}\text { Cutting } \\
\text { velocity }\end{array}$ & $\mathrm{V}_{\mathrm{c}}$ & $\mathrm{m} / \mathrm{s}$ & 22 & 28 & 34 \\
\hline Feed rate & $\mathrm{f}_{\mathrm{d}}$ & $\mathrm{m} / \mathrm{min}$ & 0.3 & 0.45 & 0.6 \\
\hline $\begin{array}{l}\text { Depth of } \\
\text { cut }\end{array}$ & $\mathrm{a}_{\mathrm{p}}$ & $\mathrm{m}$ & 0.005 & 0.001 & 0.015 \\
\hline
\end{tabular}

\begin{tabular}{|c|c|c|c|c|c|c|c|c|}
\hline \multirow{2}{*}{$\begin{array}{l}\mathrm{N} \\
\mathrm{o} .\end{array}$} & \multicolumn{3}{|c|}{$\begin{array}{l}\text { Code } \\
\text { value }\end{array}$} & \multicolumn{3}{|c|}{ Actual value } & \multirow{2}{*}{$\begin{array}{l}\mathrm{Ra} \\
(\mu \\
\mathrm{m})\end{array}$} & \multirow{2}{*}{$\begin{array}{c}\text { MRR } \\
\left(\mathrm{mm}^{3} /\right. \\
\min )\end{array}$} \\
\hline & $\begin{array}{l}\mathrm{V} \\
\mathrm{c}\end{array}$ & $\begin{array}{l}\mathrm{f} \\
\mathrm{d}\end{array}$ & $\begin{array}{l}\mathrm{a} \\
\mathrm{p}\end{array}$ & $\begin{array}{c}\mathrm{V}_{\mathrm{c}} \\
(\mathrm{m} / \mathrm{s})\end{array}$ & $\begin{array}{c}\begin{array}{c}\mathrm{fd}_{\mathrm{d}} \\
(\mathrm{m} / \mathrm{mi} \\
\mathrm{n})\end{array}\end{array}$ & $\begin{array}{c}\mathrm{ap}_{\mathrm{p}} \\
(\mathrm{mm})\end{array}$ & & \\
\hline 1 & 1 & 1 & 1 & 22 & 0.3 & $\begin{array}{c}0.00 \\
5\end{array}$ & $\begin{array}{l}1.2 \\
34\end{array}$ & 141.35 \\
\hline 2 & 1 & 1 & 1 & 22 & 0.3 & $\begin{array}{c}0.00 \\
5\end{array}$ & $\begin{array}{l}1.2 \\
35\end{array}$ & 141.35 \\
\hline 3 & 1 & 1 & 1 & 22 & 0.3 & $\begin{array}{c}0.00 \\
5\end{array}$ & $\begin{array}{l}1.2 \\
38\end{array}$ & 141.35 \\
\hline 4 & 1 & 2 & 2 & 22 & 0.45 & 0.01 & $\begin{array}{l}0.7 \\
23\end{array}$ & 423.97 \\
\hline
\end{tabular}

Table 2. L27 orthogonal matrix and results 


\begin{tabular}{|c|c|c|c|c|c|c|c|c|}
\hline \multirow[b]{2}{*}{$\begin{array}{l}\mathrm{N} \\
\mathrm{o} .\end{array}$} & \multicolumn{3}{|c|}{$\begin{array}{l}\text { Code } \\
\text { value }\end{array}$} & \multicolumn{3}{|c|}{ Actual value } & \multirow{2}{*}{$\begin{array}{l}\mathrm{Ra} \\
(\mu \\
\mathrm{m})\end{array}$} & \multirow{2}{*}{$\begin{array}{c}\text { MRR } \\
\left(\mathrm{mm}^{3} /\right. \\
\min )\end{array}$} \\
\hline & $\begin{array}{l}\mathrm{V} \\
\mathrm{c}\end{array}$ & $\begin{array}{l}\mathrm{f} \\
\mathrm{d}\end{array}$ & $\begin{array}{l}\mathrm{a} \\
\mathrm{p}\end{array}$ & $\begin{array}{c}\mathrm{V}_{\mathrm{c}} \\
(\mathrm{m} / \mathrm{s})\end{array}$ & $\begin{array}{c}\mathrm{f}_{\mathrm{d}} \\
(\mathrm{m} / \mathrm{mi} \\
\mathrm{n})\end{array}$ & $\begin{array}{c}\mathrm{ap}_{\mathrm{p}} \\
(\mathrm{mm})\end{array}$ & & \\
\hline 5 & 1 & 2 & 2 & 22 & 0.45 & 0.01 & $\begin{array}{l}0.7 \\
24\end{array}$ & 423.97 \\
\hline 6 & 1 & 2 & 2 & 22 & 0.45 & 0.01 & $\begin{array}{l}0.7 \\
24\end{array}$ & 423.97 \\
\hline 7 & 1 & 3 & 3 & 22 & 0.6 & $\begin{array}{c}0.01 \\
5\end{array}$ & $\begin{array}{l}1.2 \\
11\end{array}$ & 847.81 \\
\hline 8 & 1 & 3 & 3 & 22 & 0.6 & $\begin{array}{c}0.01 \\
5\end{array}$ & $\begin{array}{l}1.2 \\
22\end{array}$ & 847.81 \\
\hline 9 & 1 & 3 & 3 & 22 & 0.6 & $\begin{array}{c}0.01 \\
5\end{array}$ & $\begin{array}{l}1.2 \\
08\end{array}$ & 847.81 \\
\hline 10 & 2 & 1 & 2 & 28 & 0.3 & 0.01 & $\begin{array}{l}0.9 \\
78\end{array}$ & 282.65 \\
\hline 11 & 2 & 1 & 2 & 28 & 0.3 & 0.01 & $\begin{array}{c}0.9 \\
80\end{array}$ & 282.65 \\
\hline 12 & 2 & 1 & 2 & 28 & 0.3 & 0.01 & $\begin{array}{c}0.9 \\
82\end{array}$ & 282.65 \\
\hline 13 & 2 & 2 & 3 & 28 & 0.45 & $\begin{array}{c}0.01 \\
5\end{array}$ & $\begin{array}{c}0.4 \\
68\end{array}$ & 635.85 \\
\hline 14 & 2 & 2 & 3 & 28 & 0.45 & $\begin{array}{c}0.01 \\
5\end{array}$ & $\begin{array}{c}0.4 \\
69\end{array}$ & 635.85 \\
\hline 15 & 2 & 2 & 3 & 28 & 0.45 & $\begin{array}{c}0.01 \\
5\end{array}$ & $\begin{array}{l}0.4 \\
71\end{array}$ & 635.85 \\
\hline 16 & 2 & 3 & 1 & 28 & 0.6 & $\begin{array}{c}0.00 \\
5\end{array}$ & $\begin{array}{l}0.2 \\
63\end{array}$ & 282.70 \\
\hline 17 & 2 & 3 & 1 & 28 & 0.6 & $\begin{array}{c}0.00 \\
5\end{array}$ & $\begin{array}{l}0.2 \\
65\end{array}$ & 282.70 \\
\hline 18 & 2 & 3 & 1 & 28 & 0.6 & $\begin{array}{c}0.00 \\
5\end{array}$ & $\begin{array}{l}0.2 \\
67\end{array}$ & 282.70 \\
\hline 19 & 3 & 1 & 3 & 34 & 0.3 & $\begin{array}{c}0.01 \\
5\end{array}$ & $\begin{array}{l}0.7 \\
26\end{array}$ & 423.90 \\
\hline 20 & 3 & 1 & 3 & 34 & 0.3 & $\begin{array}{c}0.01 \\
5\end{array}$ & $\begin{array}{l}0.7 \\
24\end{array}$ & 423.90 \\
\hline 21 & 3 & 1 & 3 & 34 & 0.3 & $\begin{array}{c}0.01 \\
5\end{array}$ & $\begin{array}{l}0.7 \\
24\end{array}$ & 423.90 \\
\hline 22 & 3 & 2 & 1 & 34 & 0.45 & $\begin{array}{c}0.00 \\
5\end{array}$ & $\begin{array}{l}0.5 \\
22\end{array}$ & 212.02 \\
\hline 23 & 3 & 2 & 1 & 34 & 0.45 & $\begin{array}{c}0.00 \\
5\end{array}$ & $\begin{array}{l}0.5 \\
24\end{array}$ & 212.02 \\
\hline
\end{tabular}

\begin{tabular}{|c|c|c|c|c|c|c|c|c|}
\hline \multirow[b]{2}{*}{$\begin{array}{l}\mathrm{N} \\
\mathrm{o} .\end{array}$} & \multicolumn{3}{|c|}{$\begin{array}{l}\text { Code } \\
\text { value }\end{array}$} & \multicolumn{3}{|c|}{ Actual value } & \multirow{2}{*}{$\begin{array}{l}\text { Ra } \\
(\mu \\
\mathrm{m})\end{array}$} & \multirow{2}{*}{$\begin{array}{c}\text { MRR } \\
\left(\mathrm{mm}^{3} /\right. \\
\min )\end{array}$} \\
\hline & $\begin{array}{l}\mathrm{V} \\
\mathrm{c}\end{array}$ & $\begin{array}{l}f \\
d\end{array}$ & $\begin{array}{l}a \\
p\end{array}$ & $\begin{array}{c}\mathrm{V}_{\mathrm{c}} \\
(\mathrm{m} / \mathrm{s})\end{array}$ & $\begin{array}{c}\mathrm{f}_{\mathrm{d}} \\
(\mathrm{m} / \mathrm{mi} \\
\mathrm{n})\end{array}$ & $\begin{array}{c}\mathrm{ap}_{\mathrm{p}} \\
(\mathrm{mm})\end{array}$ & & \\
\hline 24 & 3 & 2 & 1 & 34 & 0.45 & $\begin{array}{c}0.00 \\
5\end{array}$ & $\begin{array}{c}0.5 \\
18\end{array}$ & 212.02 \\
\hline 25 & 3 & 3 & 2 & 34 & 0.6 & 0.01 & $\begin{array}{l}0.3 \\
21\end{array}$ & 565.30 \\
\hline 26 & 3 & 3 & 2 & 34 & 0.6 & 0.01 & $\begin{array}{l}0.3 \\
34\end{array}$ & 565.30 \\
\hline 27 & 3 & 3 & 2 & 34 & 0.6 & 0.01 & $\begin{array}{l}0.3 \\
56\end{array}$ & 565.30 \\
\hline
\end{tabular}

\section{$4 \quad$ Results and discussion}

The experiments in the order of experiments in Table 2 were conducted. The measurement results of surface roughness and MRR values have also been included in this table. In Figure 1, it is the Pareto chart of the effect of input parameters on the surface roughness. The results show that the cutting speed and feed rate have a significant effect on the surface roughness, in which the effect of cutting speed on the surface roughness is greater than the effect of feed rate. The cutting depth has an insignificant effect on the surface roughness.

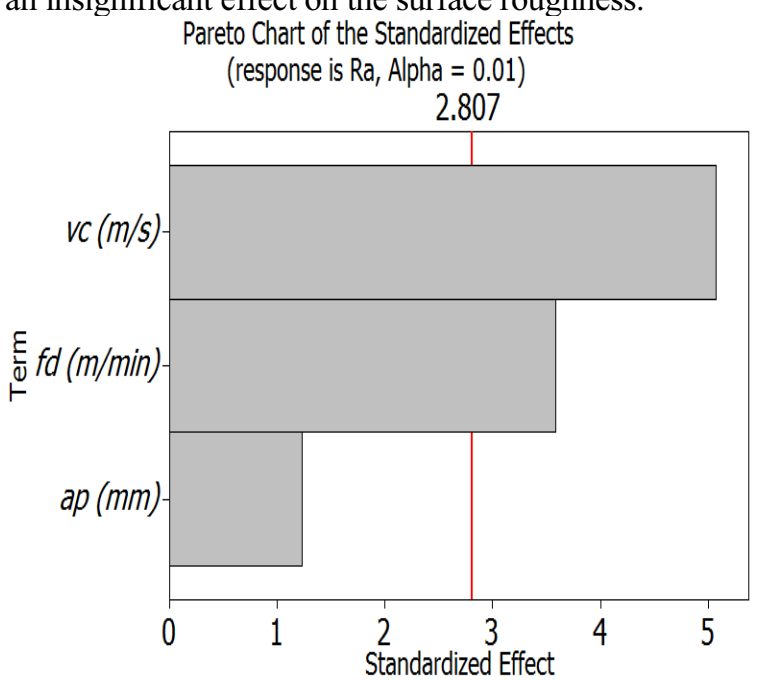

Fig. 1. Pareto Chart of the standardized effects for Ra

For MRR, increasing feed rate and cutting depth will directly increase the value of MRR while the cutting speed has no effect on MRR.

From some of the above analysis, it is shown that it is difficult to determine the value of input parameters if only observing the chart in Figure 1 to ensure the minimum 
surface roughness and the maximum MRR simultaneously. As the cutting speed has a significant effect on the surface roughness but has no effect on the MRR, the cutting depth has an insignificant impact on the surface roughness but has a significant impact in MRR. On the other hand, the data in Table 2, the maximum value of MRR is $847.81 \mathrm{~mm} 3 / \mathrm{min}$ in experiments \#7, \#8, and \#9. However, in these experiments, the surface roughness is of great value. The surface roughness has a minimum value of $0.263 \mu \mathrm{m}$ in experiment $\# 16$, but this experiment is also 3 of the experiments with the minimum value of MRR. Since then, observing the data in Table 2 is also incapable of determining the value of input parameters to simultaneously ensure the minimum surface roughness and the maximum MRR.

\section{Multi-objective optimization of grinding process}

From the experimental data in Table 2, the weight of responses and MRPI value in each experiment are calculated in accordance with the formulas from (1) to (3), as shown in Table 3.

Table 3. The weight of responses and MRPI in the experiments

\begin{tabular}{cccc}
\hline No. & $\mathbf{W}_{\mathbf{R}_{\mathbf{a}}}$ & $\mathbf{W}_{\mathbf{M R R}}$ & MRPI \\
\hline 1 & 0.0636 & 0.0839 & 11.9386 \\
2 & 0.0636 & 0.0839 & 11.9387 \\
3 & 0.0638 & 0.0839 & 11.9391 \\
4 & 0.0372 & 0.0280 & 11.8871 \\
5 & 0.0373 & 0.0280 & 11.8871 \\
6 & 0.0373 & 0.0280 & 11.8871 \\
7 & 0.0624 & 0.0140 & 11.9357 \\
8 & 0.0630 & 0.0140 & 11.9371 \\
9 & 0.0622 & 0.0140 & 11.9353 \\
10 & 0.0504 & 0.0420 & 11.9094 \\
11 & 0.0505 & 0.0420 & 11.9096 \\
12 & 0.0506 & 0.0420 & 11.9098 \\
13 & 0.0241 & 0.0187 & 11.8714 \\
14 & 0.0242 & 0.0187 & 11.8715 \\
15 & 0.0243 & 0.0187 & 11.8716 \\
16 & 0.0135 & 0.0420 & 11.8637 \\
\hline
\end{tabular}

\begin{tabular}{llll}
\hline 17 & 0.0137 & 0.0420 & 11.8638 \\
18 & 0.0138 & 0.0420 & 11.8638 \\
19 & 0.0374 & 0.0280 & 11.8873 \\
20 & 0.0373 & 0.0280 & 11.8871 \\
21 & 0.0373 & 0.0280 & 11.8871 \\
22 & 0.0269 & 0.0559 & 11.8742 \\
23 & 0.0270 & 0.0559 & 11.8743 \\
24 & 0.0267 & 0.0559 & 11.8740 \\
25 & 0.0165 & 0.0210 & 11.8655 \\
26 & 0.0172 & 0.0210 & 11.8659 \\
27 & 0.0183 & 0.0210 & 11.8667 \\
\hline
\end{tabular}

From the data in Table 3, MPRI values of all input parameters at all levels have been calculated. This value is calculated as the sum of MRPI values of each parameter at the respective levels, as shown in Table 4.

Table 4. Total MRPI values of parameters at levels

\begin{tabular}{|c|c|c|c|c|}
\hline \multirow{2}{*}{$\begin{array}{c}\text { Paramet } \\
\text { er }\end{array}$} & \multicolumn{3}{|c|}{ Level } & Max \\
\cline { 2 - 5 } & 1 & 2 & 3 & - Min \\
\hline \multirow{2}{*}{$\mathrm{V}_{\mathrm{c}}$} & $\begin{array}{c}107.285 \\
9\end{array}$ & 106.934 & 106.882 & 0.403 \\
& 9 & 1 & 8 \\
\hline \multirow{2}{*}{$\mathrm{f}_{\mathrm{d}}$} & 107.206 & 106.898 & 106.997 & 0.308 \\
& 9 & 3 & 4 & 6 \\
\hline \multirow{2}{*}{$\mathrm{a}_{\mathrm{p}}$} & 107.030 & 106.988 & 107.084 & 0.095 \\
& 1 & 3 & 2 & 9 \\
\hline
\end{tabular}

From the data in Table 4, it is shown that the cutting speed has the smallest MRPI value corresponding to level 3, feed rate, and cutting depth have the same minimum MRPI value corresponding to level 2. Thus, the optimal values of cutting speed, feed rate, and cutting depth are $34 \mathrm{~m} / \mathrm{s}, 0.45 \mathrm{~m} / \mathrm{min}$ and $0.012 \mathrm{~mm}$, respectively [19]. The Max-Min of MRPI with the maximum value of 0.4038 is of the cutting speed. Thus, if evaluating the grinding process through two parameters of surface roughness and MRR, the cutting speed is the parameter having the greatest effect on the grinding process, followed by the effect of feed rate, and the cutting depth parameter stands at the last position [19].

\section{Experiment with optimal values of parameters}

The optimal set of three input parameters determined above has been used to conduct the experiment of grinding process with three X12M steel samples. The 
surface roughness on each experiment sample has been included in Table 5. The MRR value at each experiment has also been calculated and included in this table. The average value of surface roughness in these cases is $0.316 \mu \mathrm{m}$. If compared with the surface roughness values in Table 2 , it can be seen that although $0.316 \mu \mathrm{m}$ is still larger than the value of surface roughness at experiments \#16, \#17, and \#18, it can also be seen that this value is very small compared to the rest of 27 conducted experiments. The calculated MRR value is equal to $423.97 \mathrm{~mm} 3 / \mathrm{min}$. Among the 9 MRR values in Table 2, inclusive of: $141.35,212.02,282.65,282.70,423.90,423.97$, $565.30,635.85$ and $847.81 \mathrm{~mm} 3 / \mathrm{min}$, the MRR value, when conducting the experiment with the optimal set of input parameters, is larger than five values and smaller than three values. Thus, in spite of conducting the experiment based on the optimal value of input parameters, the surface roughness is not the minimum value and the MRR is also not the maximum value when compared to 27 conducted experiments. However, the obtained surface roughness has a very small value, while the MRR has a relatively large value. This result ensures reliability when using the optimal value of input parameters and confirms the success in using the DEAR method in this study.

Table 5. Output parameters when conducting the experiment with optimal values of input parameters

\begin{tabular}{|c|c|c|c|c|c|}
\hline \multirow[b]{2}{*}{$\begin{array}{c}\text { No } \\
\text {. }\end{array}$} & \multicolumn{3}{|c|}{ Optimization value } & \multirow[b]{2}{*}{$\begin{array}{c}\mathbf{R a} \\
(\mu \mathbf{m})\end{array}$} & \multirow[b]{2}{*}{$\begin{array}{c}\text { MRR } \\
\left(\mathrm{mm}^{3} / \mathrm{mi}\right. \\
\mathrm{n})\end{array}$} \\
\hline & $\begin{array}{c}v_{c} \\
(\mathrm{~m} / \mathrm{s} \\
)\end{array}$ & $\begin{array}{c}\mathbf{f}_{\mathrm{d}} \\
(\mathrm{m} / \mathrm{min} \\
)\end{array}$ & $\begin{array}{c}a_{p} \\
(\mathrm{~mm} \\
)\end{array}$ & & \\
\hline 1 & \multirow{3}{*}{34} & \multirow{3}{*}{0.45} & \multirow{3}{*}{0.01} & $\begin{array}{c}0.32 \\
0\end{array}$ & 423.97 \\
\hline 2 & & & & $\begin{array}{c}0.31 \\
1\end{array}$ & 423.97 \\
\hline 3 & & & & $\begin{array}{c}0.31 \\
7\end{array}$ & 423.97 \\
\hline \multicolumn{4}{|c|}{ Mean } & $\begin{array}{c}0.31 \\
6 \\
\end{array}$ & 423.97 \\
\hline
\end{tabular}

\section{Conclusion}

The experimental process of grinding X12 steel has been conducted in this study. Cutting speed, feed rate, and cutting depth have been determined as the input parameters of the experimental process. The DEAR method has been applied to determine the optimal value of input parameters. Several conclusions drawn from this study are as follows:

- Among the three investigated parameters, the cutting speed is the parameter having the greatest effect on surface roughness, followed by the effect of feed rate. The cutting depth has an insignificant effect on surface roughness.

- The two parameters, including the feed rate and the cutting depth, have a great effect on MRR. Meanwhile, the cutting speed has no effect on MRR.

- If evaluating the grinding process through the two parameters of surface roughness and MRR, the cutting speed is the parameter having the greatest effect, followed by the effect of feed rate, and finally, the effect of cutting depth.

- In order to simultaneously ensure the two objectives, including the surface roughness with "minimum" value and the MRR with "maximum" value, cutting speed, feed rate and cutting depth are $34 \mathrm{~m} / \mathrm{s}, 0.45$ $\mathrm{m} / \mathrm{min}$ and $0.01 \mathrm{~mm}$, respectively.

- Dear method has been first applied to multi-objective optimization of X12M steel cylindrical grinding process. It not only has succeeded in determining the optimal value of input parameters in this study as well in published studies [20-23], but also promises to be successful in other studies when it is applied to determine the value of input parameters to simultaneously ensure multiple criteria of the machining process.

- Simultaneous determination of the optimal set of cutting parameters, dressing parameters, and cooling lubrication parameters to simultaneously ensure the minimum surface roughness and the maximum MRR is the work that the authors of this article will conduct in the next time.

\section{Acknowledgment}

This work was supported by Thai Nguyen University of Technology.

\section{References}

1. I.D. Marinescu, M.P. Hitchiner, E. Uhlmann, W.B. Rowe, I. Inasaki, Handbook of machining with grinding wheels, CRC Press, (2006). 
2. S. Malkin, C. Guo, Grinding technology: Theory and Applications of Machining with Abrasives (2nd Edition), New York: Industrial Press, (2008).

3. D. D. Trung, Influence of Cutting Parameters on Surface Roughness in Grinding of 65G Steel, Tribology in Industry, 43(1), 167-176, (2021), doi: 10.24874/ti.1009.11.20.01

4. S. M. Deshmukh, R. D. Shelke, C. V. Bhusare, Optimization of Cylindrical Grinding Process Parameters of Hardened Material using Response Surface Methodology, International Journal of Innovative Science, Engineering \& Technology, 3(11), 216-219, (2016).

5. M.S. Phadke, Quality Engineering Using Robust Design, Printice Hall, (1989).

6. S.K. Karna, R.V. Singh, R. Sahai, Application of Taguchi Method in Indian Industry, International Journal of Emerging Technology and Advanced Engineering, 2(11), 387-391, (2012).

7. Swati S Sangale, A. D. Dongare, Optimization of the parameter in cylindrical grinding of mild steel rod (EN19) by Taguchi method, International Journal of Creative and Innovative Research in All Studies, 2(4), 67-73, (2019).

8. M. Ganesan, S. Karthikeyan, N. Karthikeyan, Prediction and Optimization of Cylindrical Grinding Parameters for Surface Roughness Using Taguchi Method, IOSR Journal of Mechanical and Civil Engineering, 39-46, (2014).

9. S. Deva Prasad, S. Vishal, P. Vishwa Sai, K. Bhargav, K. Rohith, Cylindrical grinding - experimental investigation and Taguchi study of process parameters on EN31 and mild steel, IOP Conf. Series: Materials Science and Engineering, Vol. 1057, No. 012066, pp.116, (2021), doi:10.1088/1757-899X/1057/1/012066

10. Rupesh J. Karande, S.M. Jadhav, Kshitij R. Patil, R. K. Nanwatkar, Optimization of Cylindrical Grinding Machine Parameters for Minimum Surface Roughness and Maximum MRR, Global Research and Development Journal for Engineering, 2(5), 62-68, (2017).

11. Kshitij R Patil, Rupesh J Karande, Dadaso D. Mohite, Vishwas S Jadhav, Modeling and optimization of cylindrical grinding parameters for MRR and surface roughness, International journal of engineering sciences \& research technology, 6(4), 498-503, (2017).

12. Mukesh Kumar, Sukhjinder Singh, Khushdeep Goyal, To study the effect of grinding parameters on surface roughness and material removal rate of cylindrical of heat treated EN 47 steel, Journal of Mechanical Engineering, 45(2), 81-88, (2015).

13. A.Babu, I.Balaguru, A.K.Shaik Dawood, Prediction and Optimization of Process Parameters for Cylindrical Grinding of Inconel 718 Alloy using Taguchi Approach, International Journal of Engineering Research \& Technology, 3(26), 1-5, (2015).
14. Dinesh Kumar Patel, Deepam Goyal,B. S. Pabla, Optimization of parameters in cylindrical and surface grinding for improved surface fnish, Royal society open science, 5(171906), 1-11, (2017).

15. Gaurav Upadhyay, Ramprasad, Kamal Hassan, Optimization of Metal Removal Rateon Cylindrical Grinding for IS319 Brass Using Taguchi Method, International Journal of Engineering Research and Applications, 5(6), 63-67, (2015).

16. K. Mekala, J. Chandradas, K. Chandrasekaran, T. T. M. Kannan, E. Ramesh, R .Narasing Babu, Optimization of cylindrical grinding parameters of austenitic stainless steel rods (AISI 316) by Taguchi method, International journal of mechanical engineering and robotics research, 3(2), 208-215, (2014).

17. Karlapudi Gowtham, Sri. G.Gopi Nath, Optimization of Cylindrical Grinding Process Parameters on Material Removal Rate of EN21AM Steel, International journal $\&$ magazine of engineering technology management and research, 4 (8), 113-116, (2017).

18. Nidiginti.Guruchandra, B. Anjan Kumar Reddy, M. Chandra Sekhar Reddy, Optimization of Cylindrical Grinding Process Parameters on Material Removal Rate of

EN21AM steel, International Journal of Engineering Research \& Technology, 6(6), 623-631, (2017).

19. H.C. Liao, Y.K. Chen, Optimizing multi-response problem in the Taguchi method by DEA based ranking method, International Journal of Quality \& Reliability Management, 19(7), 825-837, (2002), doi: $10.1108 / 02656710210434766$

20. S. Nguyen Hong, U. Vo Thi Nhu, Multi-objective Optimization in Turning Operation of AISI 1055 Steel Using DEAR Method, Tribology in Industry, 43(1), 57-65, doi: 10.24874/ti.1006.11.20.01

21. Vennela V. K. Lakshmi, Kambagowni Venkata Subbaiah, Arun Vikram Kothapalli, Kilparthi Suresh, Parametric optimization while turning Ti-6Al-4V alloy in Mist-MQCL (Green environment) using the DEAR method, Manufacturing Review, 7(38), 1-13, (2020), doi: $10.1051 / \mathrm{mfreview} / 2020034$.

22. D. D. Trung, N.-T. Nguyen, D. H. Tien, H. L. Dang, A research on multi-objective optimization of the grinding process using segmented grinding wheel by TaguchiDear method, Eureka: Physics and Engineering, 1, 6777, (2021), doi: 10.21303/2461-4262.2021.001612.

23. V.V. Reddy, C.S. Reddy, Multi Response Optimization of EDM of AA6082 Material using Taguchi-DEAR Method, International Journal of Scientific \& Engineering Research, 7(6), 215-219, (2016).

24. Nguyen Van Thien, Hoang Tien Dung, Do Duc Trung, Ngo Cuong, Optimization Cutting Parameters When Grinding X12M Steel Using Hai Duong Grinding Wheel, International Journal of Engineering \& Technology, 7(4), 6994-6996, (2018), doi: 10.14419/ijet.v7i4.28526 